Additional information for this article can be

found in an online appendix at http://care.

diabetesjournals.org.

DOI: $10.2337 / d c-06-1393$

(C) 2006 by the American Diabetes Association.

\title{
Reversibility of Antipsychotic Treatment-Related Diabetes in Patients With Schizophrenia A case series of switching to aripiprazole
}

At present, antipsychotic drugs are not specifically referred to in the list of substances that can induce diabetes in the most recent American Diabetes Association guidelines (1), but there is a growing body of evidence that antipsychotic drugs might have diabetogenic properties $(2,3)$. At present, there are no clear guidelines on what the best therapeutic strategies are when diabetes is detected during treatment with antipsy- chotics. Data from pharmacovigilance studies suggest that a significant proportion of recent-onset cases of diabetes can be reversed. Recent Belgian guidelines for screening and monitoring patients treated with antipsychotics propose a switch to an antipsychotic with a safer metabolic profile, but this strategy has not been evaluated systematically (3). We have recently reported on five patients with treatment-emergent diabetes who were successfully switched to a more suitable antipsychotic, which resulted in the reversal of diabetes (to risperidone in one patient [4] and amisulpride in four patients [5]). Since aripiprazole, a second-generation antipsychotic agent described as having a good metabolic profile (6-8), became available on the Belgian market, all consecutive patients with recently detected diabetes were switched to this agent.

Over the last year, a switch to aripiprazole was initiated in seven consecutive patients (mean age [_SD] 37 _ 14 years) after diabetes was detected and confirmed during their previous antipsychotic treatment. All patients underwent an extensive metabolic evaluation, including an oral glucose tolerance test (OGTT) at baseline and 6 weeks and 3 months of follow-up. All but two were treated with antipsychotic medication for _ 1 year. One patient was switched from a first-generation antipsychotic, one from clozapine, one from olanzapine, two from quetiapine, and two from risperidone. All cases of diabetes met criteria at $120 \mathrm{~min}$ in the OGTT. Two patients also met criteria for diabetes while fasting, and all others had impaired fasting glucose (fasting glucose between 100 and $125 \mathrm{mg} / \mathrm{dl}$ ).

All cases of recent-onset diabetes were reversed at 3 months of follow-up. Six patients had normal glucose values both in the fasting state and at $120 \mathrm{~min}$ in the OGTT. One patient had impaired glucose tolerance (glucose at $120 \mathrm{~min}$ between 140 and $200 \mathrm{mg} / \mathrm{dl}$ ) at end point. There was a significant reduction in all glucose values in the OGTT, fasting insulin, in the homeostasis model assessment of insulin resistance, and in HbAlc glycated hemoglobin, weight, waist circumference, and BMI (online appendix [available at http://care.diabetesjournals.org]).

Whether this reversibility was due to stopping the prior antipsychotic alone could not be evaluated. Although patients were included prospectively, the number of patients remains limited. The duration of the study was only 3 months, so the observed favorable evolution on metabolic parameters should be confirmed over a longer period of time. Future research should address these issues more specifically in large, multisite samples.

To our knowledge, this is the first prospective case series addressing the metabolic safety of aripiprazole using an extensive metabolic evaluation in patients with recently detected antipsychotic treatment- emergent diabetes. If during treatment with an antipsychotic severe 
metabolic abnormalities emerge, a switch to a safer metabolic agent should be considered as the first treatment option if acceptable for the patient.

\section{MARC DE HERT, MD, PHD 1 \\ LINDA HANSSENS, MS, MSPH 2 \\ RUUD VAN WINKEL, MD 1 \\ MARTIEN WAMPERS, PHD 1 \\ DOMINIQUE VAN EYCK, MD 1 \\ ANDRE SCHEEN, MD, PHD 3 \\ JOSEPH PEUSKENS, MD, PHD 1}

From the 1University Psychiatric Center, Katholieke Universiteit Leuven, Kortenberg, Belgium; the 2Department of Epidemiology and Public Health, University of Liege, Liege, Belgium; and the 3Division of Diabetes, Nutrition and Metabolic Disorders, Faculty of Medicine, University Liege, Liege, Belgium.

Address correspondence to Marc De Hert, Leuvense

Steenweg 517, 3070 Kortenberg, Belgium.

Email:

marc.de.hert@uc-kortenberg.be.

Additional information for this article can be

found in an online appendix at http://care.

diabetesjournals.org.

DOI: $10.2337 / \mathrm{dc}-06-1393$

(C) 2006 by the American Diabetes Association.

\section{References}

1. American Diabetes Association: Diagnosis and classification of diabetes mellitus (Position Statement). Diabetes Care 29 (Suppl. 1):S43-S48, 2006

2. American Diabetes Association, American Psychiatric Association, American Association of Clinical Endocrinologists, North American Association for the Study of Obesity:

Consensus development conference on antipsychotic drugs and obesity and diabetes

Consensus Statement). Diabetes Care 27:596-601, 2004

3. De Hert M, Van Eyck D, De Nayer A: Metabolic abnormalities associated with second generation antipsychotics: fact or fiction? Development of guidelines for screening and monitoring. Int Clin Psychopharmacol 21 (Suppl. 2):11-15, 2006

4. Peuskens H, De Hert M, Van Eyck D, Peuskens J: A case of reversible olanzapineinduced diabetes after switching to risperidone. Adv Schiz Clin Psych 1:31-33, 2004

5. De Hert M, Van Eyck D, Hanssens L, Wampers M, Scheen A, Peuskens J: Rapid diabetes onset and its reversal among patients treated with second generation antipsychotics (Abstract). Eur Neuropsychopharmacol 15 (Suppl. 3):S483, 2005

6. McQuade RD, Stock E, Marcus R, Jody D, Gharbia NA, Vanveggel S, Archibald D, Carson WH: A comparison of weight change during treatment with olanzapine or aripiprazole: results from a randomized, double-blind study. J Clin Psychiatry 65 (Suppl. 18):47-56, 2004

7. DeLeon A, Patel NC, Crismon ML: Aripiprazole: a comprehensive review of its pharmacology, clinical efficacy, and tolerability. Clin Ther 26:649-666, 2004

8. L'Italien G, Casey D, Ray S, Carson W, Marcus RN: Comparison of metabolic syndrome incidence among schizophrenia patients treated with aripiprazole versus olanzapine or placebo. J Clin Psychiatry. In press 